Bài báo khoa học

\title{
Đánh giá tính dễ bị tổn thương và khả năng thích ứng do xâm nhập mặn đối với sản xuất nông nghiệp trong bối cảnh biến đổi khí hậu tại khu vụ̣c cửa sông ven biển tỉnh Nam Định
}

\author{
Nguyễn Cao Văn ${ }^{1}$, Nguyễn Lê Tuấn ${ }^{1}$, Nguyễn Thục Anh ${ }^{1}$, Phạm Văn Hiếu ${ }^{1}$ \\ 1 Viện Nghiên cứu biển và hải đảo, Tổng cục Biển và Hải đảo Việt Nam, Bộ Tài nguyên \\ và môi trường; nguyencaovan.k56@gmail.com; ngletuan1618@gmail.com; \\ thucnguyen.dav@gmail.com; hieupv.env@gmail.com \\ * Tác giả liên hệ: hieupv.env@gmail.com; Tel.: +84-986967661
}

Ban Biên tập nhận bài: 20/7/2020; Ngày phản biện xong: 15/8/2020; Ngày đăng: 25/8/2020

Tóm tắt: Nghiên cứu đưa ra kết quả phân tích, đánh giá về tính dễ bị tổn thương của yếu tố xâm nhập mặn đến sản xuất nông nghiệp và khả năng thích ứng của ngành nông nghiệp ở Nam Định trong bối cảnh biến đổi khí hậu dựa trên các số liệu khảo sát thực tế, bộ chỉ số đánh giá và mô hình thủy văn. Trong đó, mô hình thủy văn tính toán chỉ số độ mặn trong các giai đoạn theo kịch bản biến đổi khí hậu năm 2016 của Bộ Tài nguyên và Môi trường và bộ chỉ số đánh giá được xây dựng dựa trên báo cáo của Ban Liên chính phủ về Biến đổi khí hậu năm 2007 và một số các tài liệu liên quan khác. Trên cơ sở đó, nghiên cứu đã đánh giá được khả năng thích ứng của ngành nông nghiệp; diễn biến xâm nhập mặn tại 3 cửa sông Ba Lạt, Ninh Cơ và Đáy (tỉnh Nam Định); đưa ra đánh giá mức độ tổn thương của từng huyện ven biển. Tuy chưa xét được hết tất cả các khía cạnh nhưng các kết quả nghiên cứu đã góp phần cung cấp thông tin cho tỉnh Nam Định, phục vụ kế hoạch và quy hoạch ngành nông nghiệp trước bối cảnh biến đổi khí hậu.

Từ khóa: Tính dễ bị tổn thương; Xâm nhập mặn; Nông nghiệp; Cửa sông ven biển.

\section{Mở đầu}

Theo định nghĩa của Tổ chức Liên chính phủ về biến đổi khí hậu (IPCC) đưa ra năm 2007 [1] "Tính dễ bị tổn thương" (TDBTT) là mức độ mà hệ thống dễ bị tác động và không có khả năng chống chịu trước những tác động bất lợi (bao gồm các hình thái thời tiết cực

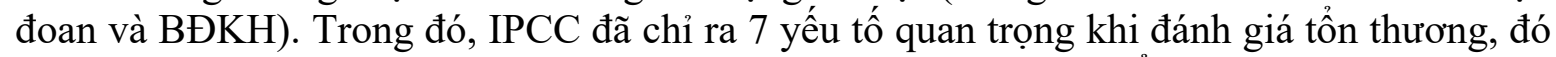
là: (1) cường độ tác động; (2) thời gian tác động; (3) mức độ dai dẳng và tính thuận nghịch của tác động; (4) mức độ tin cậy trong đánh giá tác động và tính dễ bị tổn thương; (5) năng lực thích ứng; (6) sự phân bố các khía cạnh của tác động và tính dễ bị tổn thương, và (7) tầm quan trọng của hệ thống khi gặp nguy hiểm. Các yếu tố này có thể được sử dụng kết hợp với việc đánh giá những hệ thống có độ nhạy cảm $(\mathrm{S})$ cao với các điều kiện về khí hậu như đới ven biển, hệ sinh thái, các chuỗi thức ăn,...[2].

Hiện nay, các nghiên cứu về TDBTT do biến đổi khí hậu (BĐKH) đã rất phong phú, nhưng các nghiên cứu từng thành phần trong $\mathrm{B} Đ K H$ lại rất khiêm tốn. Theo kịch bản biến đổi khí hậu và nước biển dâng, sự gia tăng nhiệt độ, biến động lượng mưa và nước biển dâng (NBD) là những mối đe dọa lớn đối với Việt Nam trong tương lai không xa [1]. Cùng với mực NBD, tình trạng hạn hán và xâm nhập mặn $(\mathrm{XNM})$ đang gia tăng rõ rệt tại nhiều vùng trên cả nước [3]. Trong khi đó, XNM tác động tiêu cực đến hàng loạt các lĩnh vực chính bao gồm sản xuất nông nghiệp, hệ sinh thái, môi trường và cơ sở hạ tầng [4], đặc biệt ngành nông 
nghiệp tại những vùng cửa sông ven biển của Việt Nam. Vì vậy hướng nghiên cứu về XNM đang là hướng nghiên cứu mới cho các nhà nghiên cứu.

Để nghiên cứu đánh giá tác động của XNM đến nông nghiệp, nhóm tác giả đã sử dụng 6 phương pháp trong đó 2 phương pháp chủ đạo, xuyên suốt để đi đến kết luận là ứng dụng mô hình tính toán thủy văn (MIKE11) và phương pháp đánh giá tính dễ bị tổn thương [1]. Với các mục tiêu: Xây dựng được bộ chỉ số đánh giá tính dễ bị tổn thương do XNM đến nông nghiệp; Xây dựng được mô hình lan truyền mặn tại các cửa sông; Đánh giá khả năng thích ứng của ngành nông nghiệp tại các khu vực ven biển trước bối cảnh XNM gia tăng.

\section{Phương pháp nghiên cứu và tài liệu thu thập}

\subsection{Phạm vi nghiên cứu}

Khu vực nghiên cứu gồm 3 huyện Giao Thủy, Hải Hậu và Nghĩa Hưng thuộc địa bàn tỉnh Nam Định, đây là vùng đất thấp, với phần lớn diện tích có độ cao dưới $2,5 \mathrm{~m}$ so với mực nước biển. Trong đó có phần nước mặt thuộc 3 cửa sông là cửa $\mathrm{Ba}$ Lạt, cửa Ninh Cơ, cửa Đáy và không gian phần đất liền tính từ đường mép nước biển thấp nhất trung bình trong nhiều năm đến đường ranh giới phân chia 3 huyện trên với các huyện khác thuộc tỉnh Nam Định [5].

Ngành nông nghiệp tỉnh Nam Định là ngành chiếm tỉ trọng lớn với gần $18 \%$ giá trị sản xuất toàn tỉnh tương đương với hơn 25.000 nghìn tỉ đồng.

\subsection{Dũ liệu}

Để chạy mô hình tính toán thủy văn (MIKE11), nghiên cứu kế thừa số liệu thủy văn từ báo cáo của Vũ Việt Đức [6]; Số liệu mặt cắt địa hình kế thừa từ dự án phòng chống lũ Đồng bằng sông Hồng của Viện Khoa học Thủy lợi (Bảng 1); Số liệu kiểm định mô hình từ số liệu khảo sát Đề tài "Đánh giá tác động của biến đổi khí hậu đến điều kiện tự nhiên, tài nguyên thiên nhiên và môi trường khu vực cửa sông ven biển vùng đồng bằng sông Hồng và đề xuất giải pháp khai thác sử dụng hợp lý - BĐKH.33/16-20" của Viện Nghiên cứu biển và hải đảo. Để tính toán bộ chỉ số đánh giá TDBTT do XNM đến nông nghiệp, dữ liệu cũng được lọc ra từ khảo sát từ Đề tài của Viện Nghiên cứu biển và hải đảo.

Bảng 1. Số lượng mặt cắt địa hình lòng dẫn sông.

\begin{tabular}{clcc}
\hline STT & Tên sông & Số mặt cắt & Năm đo \\
\hline 1 & Sông Hồng & 112 & 2017 \\
2 & Sông Đào & 18 & 2011 \\
3 & Sông Ninh Cơ & 27 & 2011 \\
4 & Sông Đáy & 54 & 2011 \\
\hline
\end{tabular}

Căn cứ vào các tài liệu và số liệu đã có, nghiên cứu đã đưa ra bộ số liệu thủy văn như sau:

- Biên trên: Các số liệu lượng dòng chảy $\left(\mathrm{m}^{3} / \mathrm{s}\right)$ được đo tại trạm khống chế phía thượng lưu Q(t). Số liệu biên trên gồm 4 vị trí: Sông Hồng tại mặt cắt nơi độ dài là $154113 \mathrm{~m}$, cách cửa $\mathrm{Ba}$ Lạt 82,6 km và sông Đáy tại vị trí $156745 \mathrm{~m}$, cách cửa Đáy khoảng 79,6km.

- Biên dưới: Các số liệu mực nước triều $(\mathrm{m})$ tại các trạm khống chế phía hạ lưu $\mathrm{H}(\mathrm{t})$. Số liệu biên dưới gồm 3 vị trí: Sông Đáy tại vị trí mặt cắt 236310 m, sông Ninh Cơ tại vị trí mặt cắt $52212 \mathrm{~m}$ và sông Hồng (cửa $\mathrm{Ba}$ Lạt) tại vị trí mặt cắt $236757 \mathrm{~m}$. Số liệu mực nước trước 
khi cho vào mô hình để tính toán đã được hiệu chỉnh theo kịch bản $\mathrm{BĐKH} \mathrm{và} \mathrm{NBD} \mathrm{(2016)}$ RCP 4.5 (Bảng 2). Các năm chạy tương ứng với nhưng năm 2030, 2050 và 2100.

- Biên mặn: Các số liệu về độ mặn (\%o) được thu thập trong khoảng đầu tháng 1, ứng với đúng một trong hai tháng kiệt nhất. Số liệu mặn được lấy từ các mặt cắt dọc theo các con sông tại khu vực nghiên cứu.

Bảng 2. Mực nước biển dâng theo kịch bản RCP 4.5 [1].

\begin{tabular}{cccc}
\hline \multirow{2}{*}{ Năm } & \multicolumn{3}{c}{ Kịch bản BĐKH - NBD 2016 (Kịch bản RCP 4.5) } \\
\cline { 2 - 4 } & $\mathbf{2 0 3 0}$ & $\mathbf{2 0 5 0}$ & $\mathbf{2 1 0 0}$ \\
\hline Mực nước dâng $(\mathrm{cm})$ & 13 & 23 & 55 \\
\hline
\end{tabular}

\subsection{Phuoong pháp nghiên cúu}

Nghiên cứu đã lựa chọn và sử dụng 6 phương pháp như sau:

- Phương pháp kế thừa và tổng hợp tài liệu: Phương pháp này được sử dụng trong việc tổng hợp và kế thừa các kết quả nghiên cứu về đặc điểm khí tượng thuỷ văn, đặc điểm địa chất, địa mạo, môi trường, các dạng tài nguyên, yếu tố xã hội...

- Phương pháp điều tra khảo sát thực địa: Phương pháp này được sử dụng phổ biến trong hầu hết các đề tài, vì nó giúp thị sát tình hình thực tế, có cái nhìn khách quan khi tiến hành đánh giá, đồng thời bổ sung được những nội dung, những thông tin mà các đề tài trên tài liệu chưa phản ánh được hết.

- Phương pháp và quy trình đánh giá tính dễ bị tổn thương dưới tác động của xâm nhập mặn: Tính dễ bị tổn thương là hàm số của đặc tính, quy mô và tốc độ của biến đổi khí hậu và nhiễu động mà một hệ thống bị lộ diện, tính nhạy cảm và năng lực thích ứng của hệ thống đó (Công thức 1). Tính dễ bị tổn thương được xem xét dựa trên 3 yếu tố là tình trạng dễ bị ảnh hưởng (Exposure), độ nhạy cảm (Sensitivity) và năng lực thích ứng (Adaptive capacity) [7]. Dưới đây là hàm đánh giá TDBTT, môi tương quan được mô tả cụ thể tại Hình 1.

$\mathrm{V}$ (Tính dễ bị tổn thương $)=f($ Exposure (tình trạng dễ bị ảnh hưởng), Sensivity (độ nhay cảm), Adaptive capacity (năng lục thich úng))

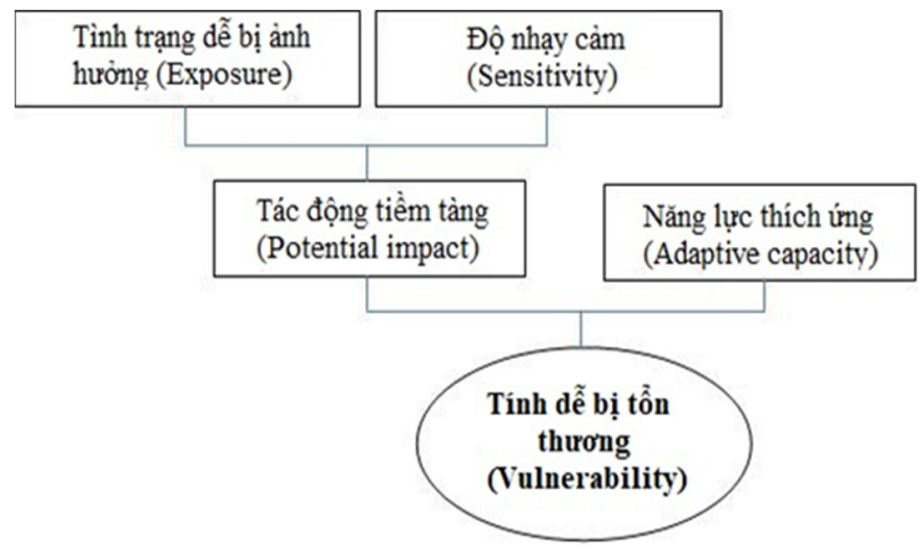

Hình 1. Phương pháp đánh giá tính dễ tổn thương [7].

Quy trình đánh giá được chia thành 6 bước (Hình 2). 


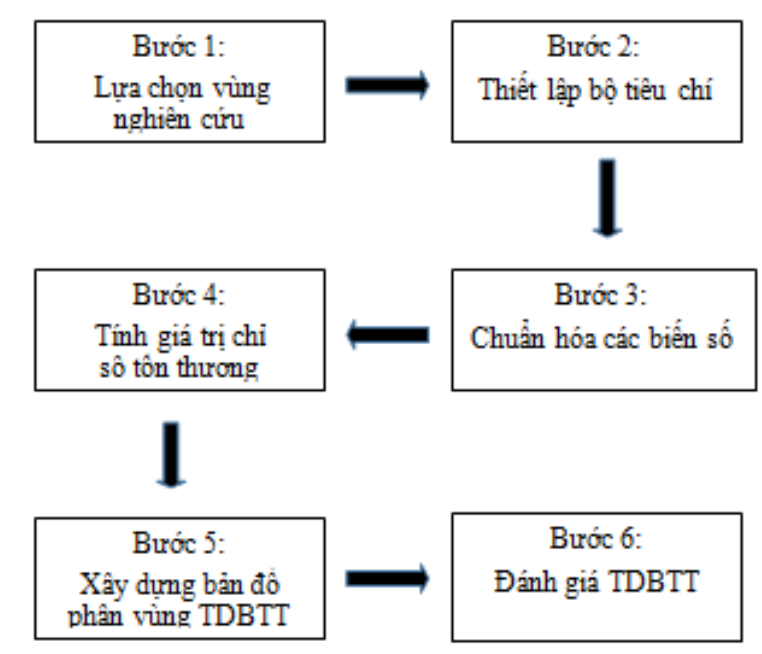

Hình 2. Quy trình đánh giá tính dễ bị tổn thương.

- Ứng dụng mô hình MIKE 11 trong việc phân tích xâm nhập mặn:

MIKE 11 là một phần mềm kỹ thuật chuyên dụng mô phỏng lưu lượng, chất lượng nước và vận chuyển bùn cát ở cửa sông, sông, hệ thống tưới, kênh dẫn và các hệ thống dẫn nước khác. Do vậy, mô hình giải quyết những bài toán liên quan thông qua các mô đun độc lập được tích hợp lại với nhau để thực hiện các quy trình tính toán cần thiết. Để nghiên cứu, chúng tôi sử dụng 2 mô đun là mô đun thuỷ lực $(H y d r o d y n a m i c-H D)$ và mô đun tải khuyếch tán (Advection Dispersion - AD).

- Ứng dụng hệ thống thông tin địa lý (GIS) trong việc xây dựng bản đồ phân vùng tính dễ bị tổn thương:

Với ưu điểm mang tính khái quát cao, phương pháp tích hợp bản đồ đã bổ sung một cách có hiệu quả khi kết hợp với các thông tin thu thập từ phiếu điều tra xã hội học và các thông tin khảo sát thực địa. Từ đó, cơ sở dữ liệu các hợp phần tự nhiên được thể hiện dưới dạng bản đồ là những đặc trưng có tính ổn định theo thời gian, sự tích hợp chúng là bức tranh đầy đủ nhất về mức độ tổn thương tại vùng nghiên cứu, đặc biệt xét theo tiêu chí (E) và (S). Nhìn chung, dựa trên phương pháp này,có thể khoanh vùng các khu vực đồng nhất tương đối về mức độ tổn thương.

- Phương pháp chuyên gia: được sử dụng hầu hết trong các quá trình xây dựng và đánh giá của nghiên cứu. Đặc biệt ý kiến của các chuyên gia rất quan trọng trong việc xây dựng nên bộ chỉ số cho các yếu tố gây tổn thương như (E), (S), (AC).

\section{Kết quả và thảo luận}

\subsection{Tác động của xâm nhập mặn đến ngành nông nghiệp và khả năng thích ứng}

BĐKH nói chung hay nước biển dâng $(\mathrm{NBD})$ và XNM nói riêng đã và đang là vấn đề nan giải với ngành nông nghiệp tại vùng ven biển tỉnh Nam Định. Nghiên cứu đưa ra một số tác động trực tiếp như: Làm giảm diện tích đất cảnh tác; Giảm năng suất, chất lượng cây trồng, vật nuôi, gia tăng chi phí sản xuất và giảm sức cạnh tranh của sản phẩm; Ảnh hưởng đến đa dạng sinh học và nguồn lợi thủy sản; Suy giảm khả năng canh tác và mất khả năng canh tác. 
Theo báo cáo của Kế hoạch ứng phó biến đổi khí hậu của tỉnh Nam Định, các huyện là Giao Thủy, Nghĩa Hưng, Hải Hậu hằng năm có khoảng 12 nghìn ha đất canh tác bị nhiễm mặn, trong đó có khoảng 5 nghìn ha nhiễm mặn, không sản xuất được. Hay nhiều loài đặc hữu bị suy giảm nghiêm trọng như: cá Chuối sộp, cua Giận, cò Thìa, ... Sự dâng lên của nước biển kiến mặn lấn sâu vào đất liền, gây ngập úng thường xuyên khu vực Cồn Lu và Cồn Ngạn huyện Giao Thủy, làm chết rừng phi lao, làm thu hẹp diện tích rừng ngập mặn [8].

XNM còn tác động mạnh hơn khi cộng hưởng từ các điều kiện thời tiết. Độ mặn là yếu tố quan trọng hàng đầu trong nghề nuôi trồng thủy sản, Việc thay đổi độ mặn trong ao do mưa kéo dài và NBD theo chiều hướng tăng hay giảm một cách đột ngột sẽ dẫn tới vật nuôi bị sốc, chậm lớn và nặng hơn là có thể chết. Nhưng bão và áp thấp nhiệt đới gây mưa lớn, sóng mạnh và kéo theo nước biển tràn vào bờ có thể tàn phá hệ thống đê bao, các ao nuôi và lồng bè nuôi, tác động đến cả hệ sinh thái của vùng nuôi, mất nhiều thời gian để phục hồi.

Hạn hán ngoài ảnh hưởng tới trồng trọt một cách rõ ràng mà mắt thường cũng có thể thấy được như làm cây trồng chết do thiếu nước, làm giảm nguồn nước tưới,... thì XNM khi lấn sâu vào đất liền dẫn đến cường hóa ảnh hưởng càng nặng nề. Trong nuôi trồng thủy sản cũng gây ảnh hưởng tương tự, hạn hán làm thiếu nước cung cấp cho các ao hồ nuôi trồng thủy sản, làm gia tăng nhiệt độ dẫn đến thay đổi môi trường sống của các loại thủy hải sản. Nói sâu hơn, nó làm thay đổi quá trình trao đổi chất, tốc độ phát triển, sinh sản của các sinh vật sống trong nước, làm chúng trở nên dễ nhiễm bệnh. Ngoài ra, hạn hán làm bốc hơi nước, dẫn đến độ mặn cao lại càng cao thêm.

\subsection{Khả năng thích úng của ngành nông nghiệp}

Trước bối cảnh XNM mặn nói riêng và NBD nói chung đang ngày càng gia tăng trong tương lai. Nhiều biện pháp thích ứng đã được tỉnh đưa ra, trong đó các 3 biện pháp về công trình điển hình như (1) Xây dựng công trình trữ ngọt ngăn mặn; (2) Xây dựng công trình cấp nước phục vụ sản xuất nông nghiệp và nuôi trồng thuỷ sản; (3) Nâng cấp hệ thống đê và công trình trên đê.

Năm 2012, Bộ Nông nghiệp và phát triển nông thôn (NN\&PTNT) đã phê duyệt Dự án “Quy hoạch tổng thể thuỷ lợi đồng bằng sông Hồng có xét đến BĐKH-NBD đến năm 2020 và định hướng đến năm 2050”, theo đó có 10 công trình ngăn mặn, trữ ngọt được đề xuất (Bảng 3). Cũng theo báo cáo, hệ thống đê điều giúp phòng chống lụt bão đã được hình thành từ lâu, từng bước được bổ sung, tu sửa, nâng cấp đến nay đã có $663 \mathrm{~km}$ đê. Đê cấp I đến cấp III có $365 \mathrm{~km}$ (91 km đê biển, $274 \mathrm{~km}$ đê sông), 298 km đê dưới cấp III, với với khoảng 100 $\mathrm{km}$ kè bảo vệ tuyến đê sông và đê biển [4].

Bảng 3. Tổng hợp đề xuất xây dựng công trình trữ ngọt ngăn mặn [8].

\begin{tabular}{clll}
\hline TT & \multicolumn{1}{c}{ Tên công trình } & \multicolumn{1}{c}{ Địa điểm (xã, huyện, tỉnh) } & Lưu vực \\
\hline \multirow{2}{*}{1} & Cống đập sông Đào & Nam Phong - Nam Trực - N.Định và Mỹ & sông Hồng \\
& Tân - Mỹ Lộc - Nam Định & Nông \\
2 & Cồng Quần Liêu & Nghĩa Sơn - Nghĩa Hưng - Nam Định & sồng \\
\hline \multirow{2}{*}{3} & Âu Kim Đài & $\begin{array}{l}\text { Thượng Kiệm }- \text { Kim Sơn }- \text { N.Bình và Kim } \\
\text { Chính }- \text { Kim Sơn }- \text { N.Bình }\end{array}$ & \multirow{2}{*}{ sông Đáy }
\end{tabular}




\begin{tabular}{cclc}
\hline TT & \multicolumn{1}{c}{ Tên công trình } & \multicolumn{1}{c}{ Địa điểm (xã, huyện, tỉnh) } & Lưu vực \\
\hline \multirow{2}{*}{4} & \multirow{2}{*}{ Cống đập sông Hồng } & $\begin{array}{l}\text { Phà Cồn Nhất thuộc Hồng Tiến - Kiến } \\
\text { Xương và Ngô Đồng - Giao Thuỷ }\end{array}$ & sông Hồng \\
& \multirow{2}{*}{$\begin{array}{l}\text { Phà Thịnh Long (Nghĩa Bình }- \text { Nghĩa } \\
\text { Hưng) và Hải Châu - Hải Hậu - Nam Định }\end{array}$} & sông Hồng \\
& \multirow{2}{*}{ Cống đập sông Đáy } & $\begin{array}{l}\text { Phà Quỹ Nhất (Nghĩa Hưng- N.Định) và } \\
\text { Kim Sơn - Ninh Bình }\end{array}$ & sông Hồng \\
\hline
\end{tabular}

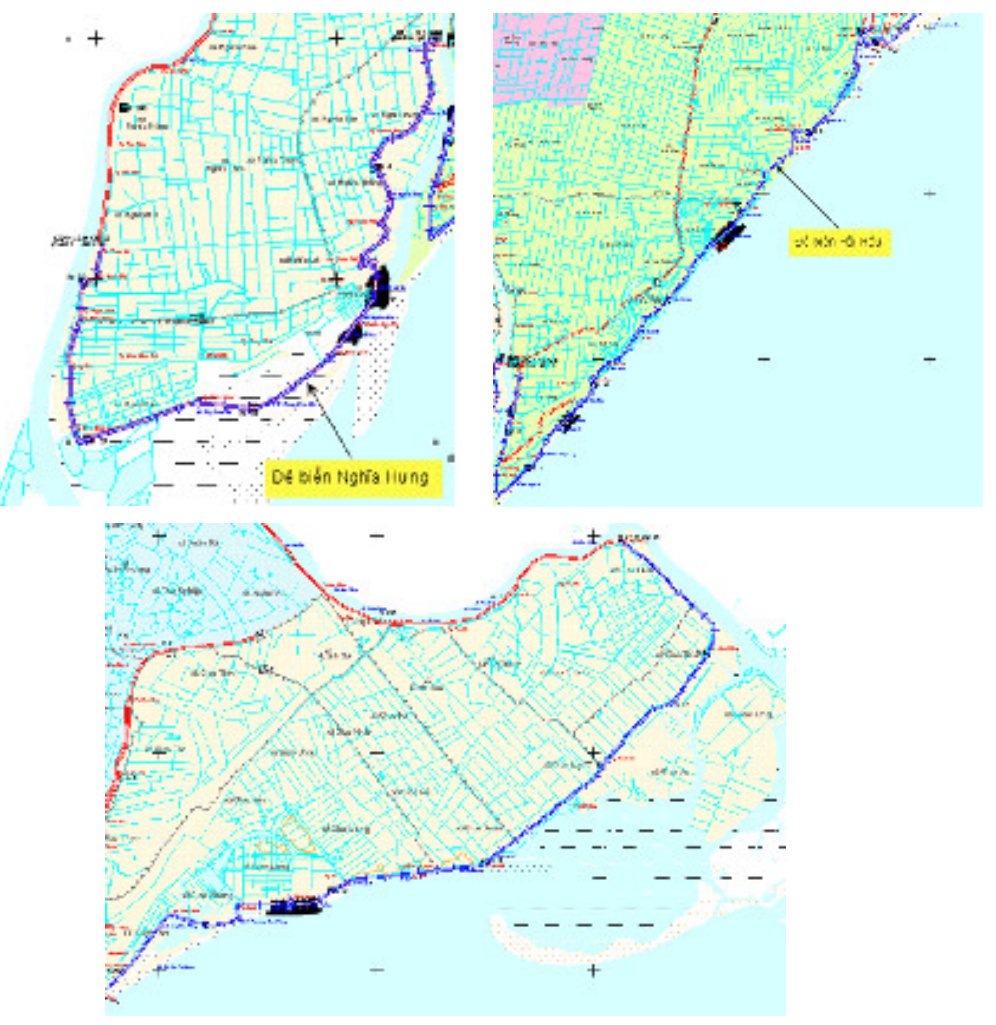

Hình 3. Đê biển tại 3 huyện Nghĩa Hưng, Hải Hậu và Giao Thủy tỉnh Nam Định [8].

Ngoài ra rất nhiều các biện pháp phi công trình khác như: (1) Vận hành hợp lý công trình lấy nước phục vụ sản xuất nông nghiệp và nuôi trồng thuỷ sản nước ngọt; (2) Tự động hóa giám sát mặn và cảnh báo, nâng cao năng lực và quản lý vận hành công trình; (3) Đổi mới quy trình công nghệ trong nông nghiệp thích ứng với xâm nhập mặn; (4) Khai thác và sử dụng hợp lý bãi bồi cửa sông ven biển; (5) Chuyển đổi giống cây trồng, vật nuôi; (6) Chuyển đổi cơ cấu sản xuất ngành nghề cho một số cộng đồng dễ bị tổn thương; (7) Nâng cao năng lực quản lý vận hành công trình; (8) Đào tạo nâng cao nhận thức cộng đồng; (9) Nghiên cứu, áp dụng khoa học công nghệ.

Ví dụ điển hình như giám sát nồng độ mặn tự động đã được áp dụng tại một số khu vực trên địa bàn tỉnh, điển hình như Xuân Thủy - Nam Định có số liệu quan trắc tức thời tại các cống này luôn được cập nhật liên tục trên trang: http://thuyloixuanthuy.vn. 


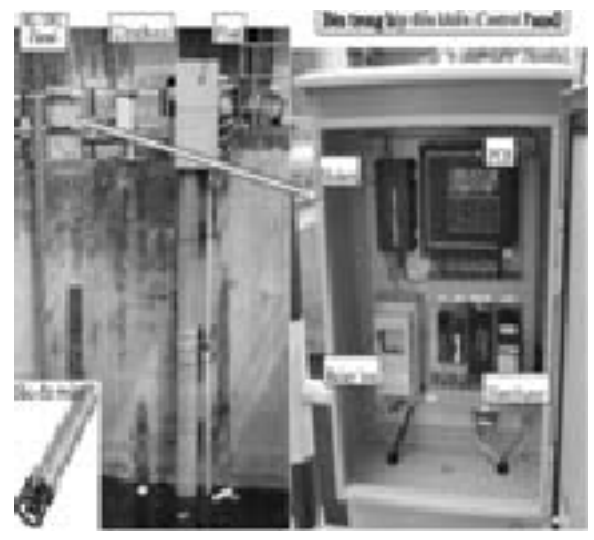

Hình 1. Hệ thống giám sát mặn tự động tại TTN Xuân Thuỷ - Nam

Định.

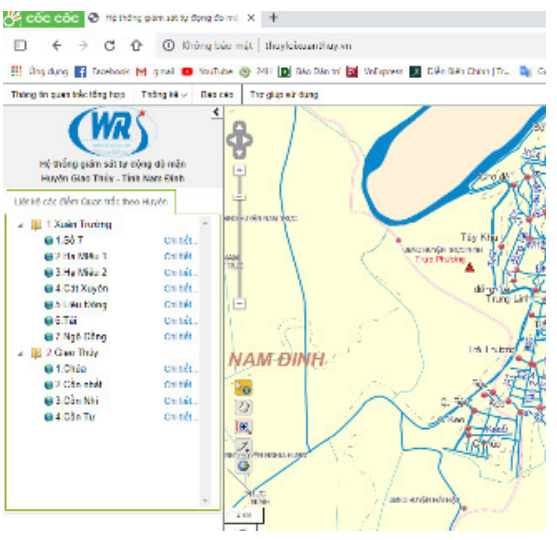

Hình 2. Giao diện trang web cập nhật số liệu quan trắc mặn.

\subsection{Diễn biến xâm nhập mặn theo mô hình MIKE 11}

Sau khi tổng hợp đủ số liệu phục vụ tính toán, số liệu sẽ được đưa vào mô hình MIKE11 chạy với kịch bản trung bình thấp (RCP4.5). Kết quả cho ra tương đối chuẩn xác khi xét hệ số tương quan giữa số liệu đầu ra mô hình với số liệu thực đo (Bảng 4). Từ kết quả đó, diễn biến XNM tại các cửa sông tỉnh Nam Định được xét theo 2 khía cạnh: khoảng cách và thời gian.

Bảng 2. Chỉ số đánh giá độ tương quan.

\begin{tabular}{cccc}
\hline Tên sông & Sông Hồng & Sông Ninh Co & Sông Đáy \\
\hline Hệ số tương quan & 0,73 & 0,79 & 0,76 \\
\hline
\end{tabular}

Theo tổ chức $\mathrm{FAO}$, chỉ ra rằng nông nghiệp khi nước có độ mặn lớn hơn $1.5 \%$ sẽ gây ảnh hưởng đến hoạt động sản xuất [1]. Do vậy, nghiên cứu xét đến các vị trí độ mặn đạt 1,5\%o trên các con sông. Kết quả cho thấy độ mặn xâm nhập vào đất liền theo các năm ngày càng tăng, trong đó sông Hồng có khoảng cách xâm nhập mặn sâu nhất. Năm 2050, độ mặn 1,5\%o xuất hiện tại vị trí $51,78 \mathrm{~km}$ tại cửa $\mathrm{Ba}$ Lạt, cửa Ninh Cơ là $33,72 \mathrm{~km}$ và cửa Đáy là 47,35 km (Hình 6-8).

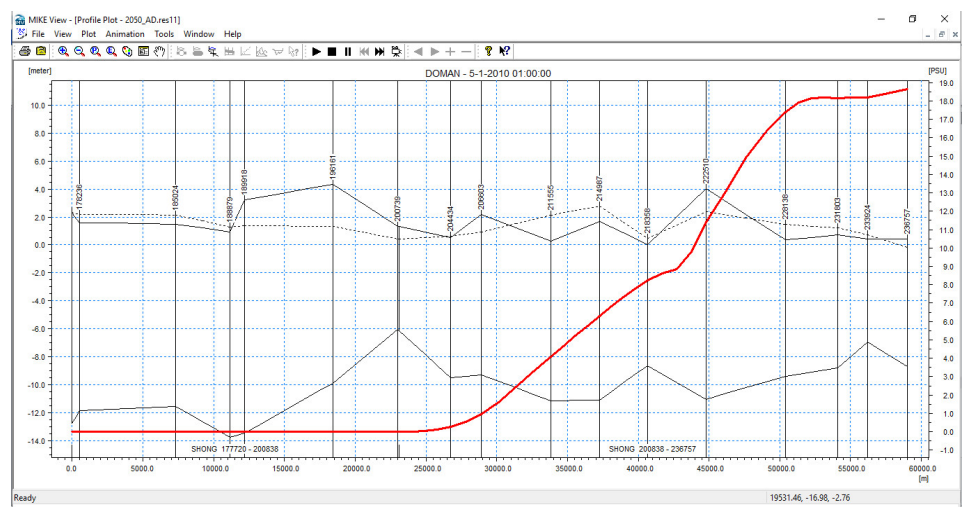

Hình 3. Diễn biến xâm nhập mặn năm 2050 tại cửa Ba Lạt theo kịch bản RCP4.5. 


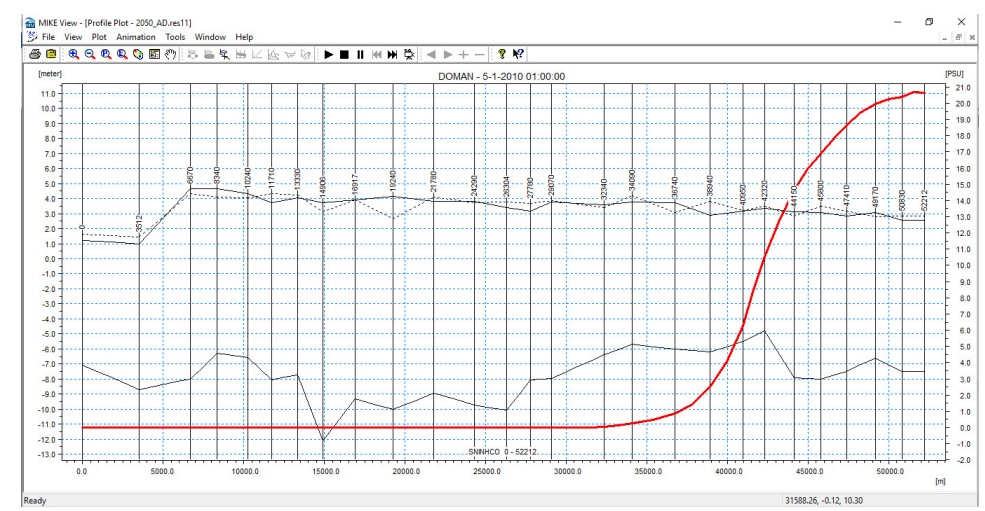

Hình 4. Diễn biến xâm nhập mặn năm 2050 tại cửa Ninh Cơ theo kịch bản RCP4.5.

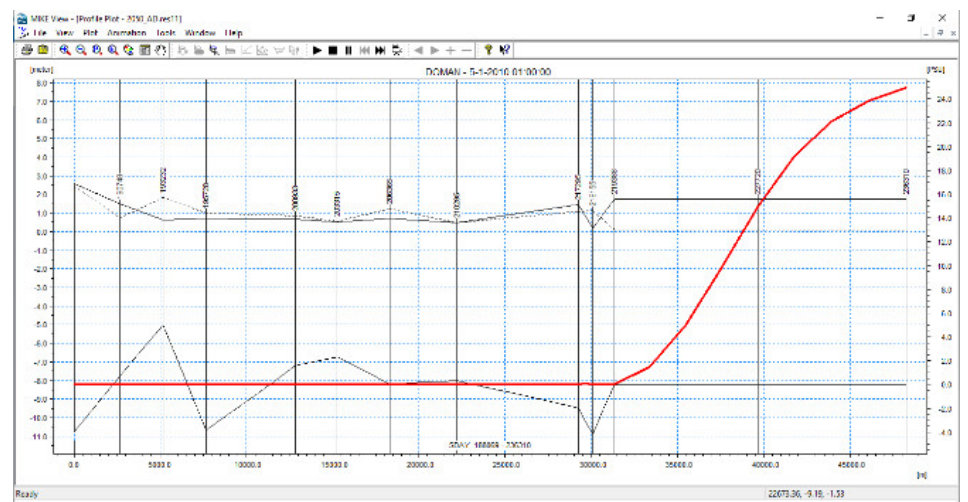

Hình 5. Diễn biến xâm nhập mặn năm 2050 tại cửa Đáy theo kịch bản RCP4.5.

Về thời gian, nghiên cứu xét theo thời gian duy trì độ mặn tại các mặt cắt sông. Kết quả cho thấy sông Hồng là sông có thời gian duy trì độ mặn liên tục dài nhất với giá trị trung bình là 156 giờ, sau đó đến sông Ninh Cơ với 15,67 giờ và cuối cùng là sông Đáy với 13,67 giờ (Bảng 5).

Bảng 3. Thời gian duy trì độ mặn 1,5\%o liên tục dài nhất tại các con sông.

\begin{tabular}{|c|c|c|c|c|}
\hline \multirow{2}{*}{ Sông } & \multicolumn{3}{|c|}{ Khoảng thời gian duy trì độ mặn liên tục $1,5 \%$} & \multirow{2}{*}{ Trung bình } \\
\hline & $5 \mathrm{~km}$ & 10 km & $15 \mathrm{~km}$ & \\
\hline Hồng & 207 & 154 & 107 & 156 \\
\hline Ninh Cơ & 34 & 13 & 0 & 15,67 \\
\hline Đáy & 31 & 10 & 0 & 13,67 \\
\hline
\end{tabular}

3.4. Đánh giá tính dễ bị tổn thương do xâm nhập mặn đến lĩnh vực nông nghiệp

\subsubsection{Kết quả tính toán độ phơi nhiễm $(\mathrm{E})$}

Bộ chỉ số $(\mathrm{E})$ trong nghiên cứu chỉ mức độ tác động XNM và các yếu tố ảnh hưởng đến XNM do BĐKH gây ra. Bộ chỉ số xây dựng gồm 3 biến phụ với 18 hợp phần phụ (Bảng 6). 
Bảng 4. Chỉ số phơi nhiễm (E) với vấn đề xâm nhâp mặn.

\begin{tabular}{|c|c|c|c|}
\hline Biến chính & Biến phụ & $\begin{array}{l}\text { Hợp phần phụ } \\
\text { (Biến thành phần) }\end{array}$ & Kí hiệu \\
\hline \multirow{18}{*}{$\begin{array}{c}\text { Độ phơi nhiễm } \\
\text { (E) }\end{array}$} & \multirow{4}{*}{$\begin{array}{c}\text { Độ mặn } \\
\left(E_{1}\right)\end{array}$} & Thời gian nhiễm mặn trên 1,5\%o & $E_{11}$ \\
\hline & & Thời gian nhiễm mặn trên 4\%o & $E_{12}$ \\
\hline & & Chiều dài sông nhiễm mặn trên $1,5 \%$ (tại điểm sâu nhất) & $E_{13}$ \\
\hline & & Chiều dài sông nhiễm mặn trên 4\%o (tại điểm sâu nhất) & $E_{14}$ \\
\hline & \multirow{4}{*}{$\begin{array}{l}\text { Hiện tượng } \\
\left.\text { thời tiết ( } E_{2}\right)\end{array}$} & Khô hạn (Tăng) & $E_{21}$ \\
\hline & & Nước biển dâng (Theo kịch bản RCP4.5 năm 2030) & $E_{22}$ \\
\hline & & Triều cường (Tăng) & $E_{23}$ \\
\hline & & Bão lũ, sóng lớn (Tăng) & $E_{24}$ \\
\hline & \multirow{10}{*}{$\begin{array}{l}\text { Tổng thể mức } \\
\text { độ bị ảnh } \\
\text { hưởng }\left(\mathrm{E}_{3}\right)\end{array}$} & Diện tích đất có nguy cơ ngập (với mực NBD $50 \mathrm{~cm}$ ) & $E_{31}$ \\
\hline & & Diện tích cây lương thực có hạt & $E_{32}$ \\
\hline & & Diện tích cây ngắn ngày (ngô, khoai, sắn) & $E_{33}$ \\
\hline & & Diện tích cây hàng năm & $E_{34}$ \\
\hline & & Diện tích cây trồng lâu năm & $E_{35}$ \\
\hline & & Diện tích rừng hiện có & $E_{36}$ \\
\hline & & Diện tích nuôi trồng thủy sản & $E_{37}$ \\
\hline & & Số lượng gia cầm & $E_{38}$ \\
\hline & & Số lượng gia súc (Trâu, bò, lợn) & $E_{39}$ \\
\hline & & Số lượng trang trại & $E_{310}$ \\
\hline
\end{tabular}

Nam Định là một tỉnh dựa chủ yếu vào nông nghiệp nên diện tích đất nông nghiệp chiếm phần lớn diện tích của 3 huyện. Với mức độ $\mathrm{BĐKH}$ và $\mathrm{NBD}$ dâng như hiện nay và kết quả từ khảo sát cũng như mô hình mô phỏng đã cho thấy quá trình XNM của 3 khu vực là rất khác nhau. Điều này đã được thể hiện rõ ràng hơn qua kết quả tỉnh toán độ chỉ số phơi nhiễm của 3 huyện. Kết quả cho thấy huyện Nghĩa Hưng là huyện chịu ảnh hưởng năng nhất so với mặt bằng các huyện khác (Bảng 7).

Bảng 5. Kết quả tính toán chỉ số độ phơi nhiễm $\mathrm{E}$.

\begin{tabular}{cccc}
\hline Độ phơi nhiễm & Giao Thủy & Hải Hậu & Nghĩa Hưng \\
\hline $\mathrm{E}_{1}$ & 0.32 & 0.00 & 0.57 \\
$\mathrm{E}_{2}$ & 0.50 & 0.74 & 0.75 \\
$\mathrm{E}_{3}$ & 0.30 & 0.63 & 0.49 \\
$\mathbf{E}$ & $\mathbf{0 . 3 5}$ & $\mathbf{0 . 4 7}$ & $\mathbf{0 . 5 7}$ \\
\hline
\end{tabular}

Sau khi ra được kết quả, số liệu phân tích sẽ được đưa vào phần mềm Mapinfo để xử lý với mục đích ra được dạng bản đồ phân vùng độ phơi nhiễm cho khu vực ven biển tỉnh Nam Định (Hình 9). 


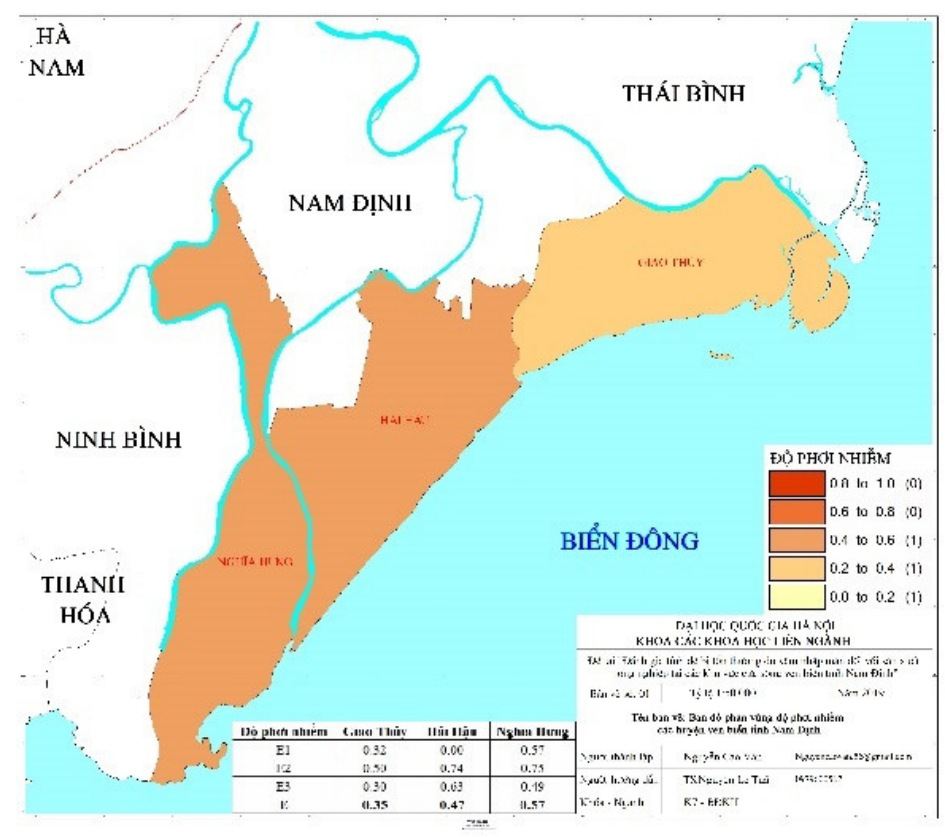

Hình 6. Bản đồ phân vùng độ phơi nhiễm E.

\subsubsection{Kết quả tính toán độ nhạy cảm (S)}

Chỉ số nhạy cảm với XMN (S) được đánh giá theo 4 biến phụ: Xã hội, sinh kế, điều kiện tự nhiên và nguồn nước; tương ứng với 23 chỉ số khác nhau được đưa vào sử dụng trong tính toán (Bảng 8).

Bảng 6. Bộ chỉ số nhạy cảm $(\mathrm{S})$ với vấn đề xâm nhập mặn.

\begin{tabular}{|c|c|c|c|}
\hline Biến chính & Biến phụ & $\begin{array}{l}\text { Hợp phần phụ } \\
\text { (Biến thành phần) }\end{array}$ & Kí hiệu \\
\hline \multirow{15}{*}{ Độ nhạy (S) } & \multirow{9}{*}{ Xã hội (S 1$)$} & Dân số trung bình & $S_{11}$ \\
\hline & & Mật độ dân số & $S_{12}$ \\
\hline & & Tỉ lệ nữ giới & $S_{13}$ \\
\hline & & Tỉ lệ dân thành thị và nông thôn & $S_{14}$ \\
\hline & & Tỉ lệ người dân làm nông nghiệp & $S_{15}$ \\
\hline & & Thu nhập của lao động (Trung bình đổ lên) & $S_{16}$ \\
\hline & & Số lao động trong cơ sở kinh tế cá thể & $S_{17}$ \\
\hline & & Tốc độ tăng trưởng dân số & $S_{18}$ \\
\hline & & Tỷ lệ hộ nghèo & $S_{19}$ \\
\hline & \multirow{6}{*}{ Sinh kế $\left(\mathrm{S}_{2}\right)$} & Sản lượng cây lương thực có hạt & $S_{21}$ \\
\hline & & Sản lượng lĩnh vực chăn nuôi (Trâu, bò, lợn) & $S_{22}$ \\
\hline & & Sản lượng ngành thủy sản & $S_{23}$ \\
\hline & & Giá trị sản xuất lâm nghiệp & $S_{24}$ \\
\hline & & Giá trị sản xuất ngành thủy sản & $S_{25}$ \\
\hline & & $\begin{array}{l}\text { Giá trị sản phẩm thu được trên } 1 \text { ha mặt nước nuôi trồng } \\
\text { thủy sản }\end{array}$ & $S_{26}$ \\
\hline
\end{tabular}




\begin{tabular}{|c|c|c|c|}
\hline Biến chính & Biến phụ & $\begin{array}{l}\text { Hợp phần phụ } \\
\text { (Biến thành phần) }\end{array}$ & Kí hiệu \\
\hline & \multirow{7}{*}{$\begin{array}{c}\text { Điều kiện tự } \\
\text { nhiên } \\
\left(\mathrm{S}_{3}\right)\end{array}$} & Giá trị sản phẩm thu được trên 1 ha đất nông nghiệp & $S_{27}$ \\
\hline & & $\begin{array}{l}\text { \% Mức độ tác động của XNM đến nông nghiệp (Tác } \\
\text { động mạnh) }\end{array}$ & $S_{28}$ \\
\hline & & Cơ giới hóa trong sản xuất nông nghiệp (Cơ giới hóa cao) & $S_{29}$ \\
\hline & & Rừng ngập mặn (Giảm) & $S_{31}$ \\
\hline & & Độ cao địa hình & $S_{32}$ \\
\hline & & Biên độ giao động mực nước & $S_{33}$ \\
\hline & & Mật độ mặt nước & $S_{34}$ \\
\hline & $\begin{array}{l}\text { Nguồn nước } \\
\qquad\left(\mathrm{S}_{4}\right)\end{array}$ & $\begin{array}{l}\text { Khả năng đáp ứng nhu cầu nước cho ngành nông nghiệp } \\
\text { (mức độ hài lòng) }\end{array}$ & $S_{41}$ \\
\hline
\end{tabular}

Dựa trên bảng kết quả tổng hợp, có thể thấy các biến phụ tính toán cho 3 huyện Giao Thủy, Hải Hậu và Nghĩa Hưng gần tương đồng nhau. Ngoại trừ một hợp phần phụ như biên độ giao động mực nước trung bình của huyện Nghĩa Hưng nhỉnh hơn nhiều so với các huyện khác, do Nghĩa Hưng là huyện nằm giữa 2 con sông Ninh Cơ và Đáy (Bảng 9).

Bảng 7. Kết quả tính toán độ nhạy cảm $\mathrm{S}$.

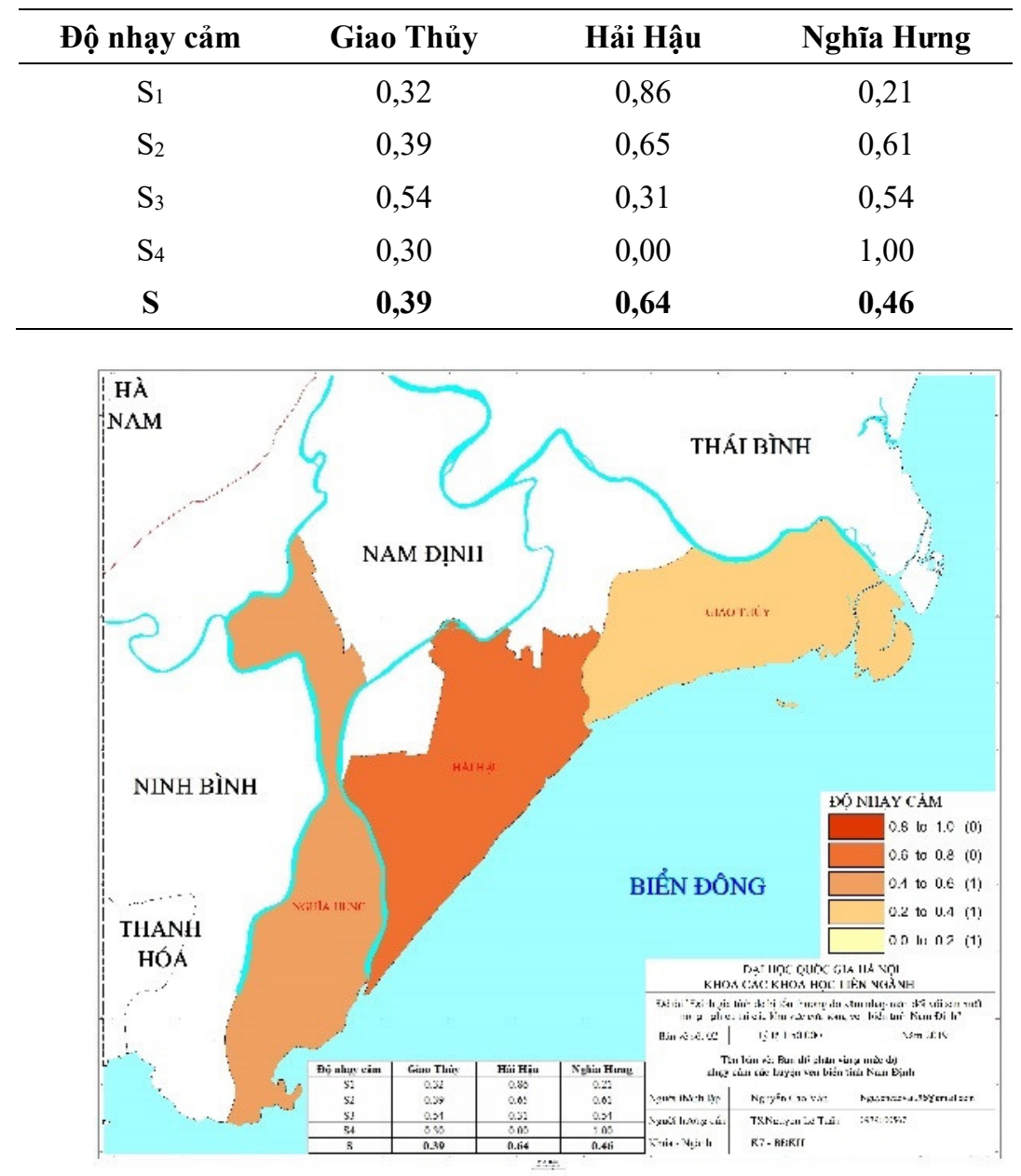

Hình 7. Bản đồ phân vùng độ nhạy cảm $S$. 


\subsubsection{Kết quả tính toán khả năng thích ứng $(\mathrm{AC})$}

Khả năng thích ứng bao gồm khả năng của các nguồn lực liên quan đến ngành nông nghiệp của vùng nghiên cứu. Để tính toán khả năng thích ứng, nghiên cứu đã lựa chọn 3 biến phụ bao gồm: cơ sở hạ tầng nông nghiệp; chính quyền; vấn đề xã hội khác. Đi kèm với 3 biến phụ là 20 hợp phần phụ để chi tiết hóa chỉ số thích ứng (Bảng 10).

Bảng 8. Bộ chỉ số thích ứng (AC) với vấn đề xâm nhập mặn.

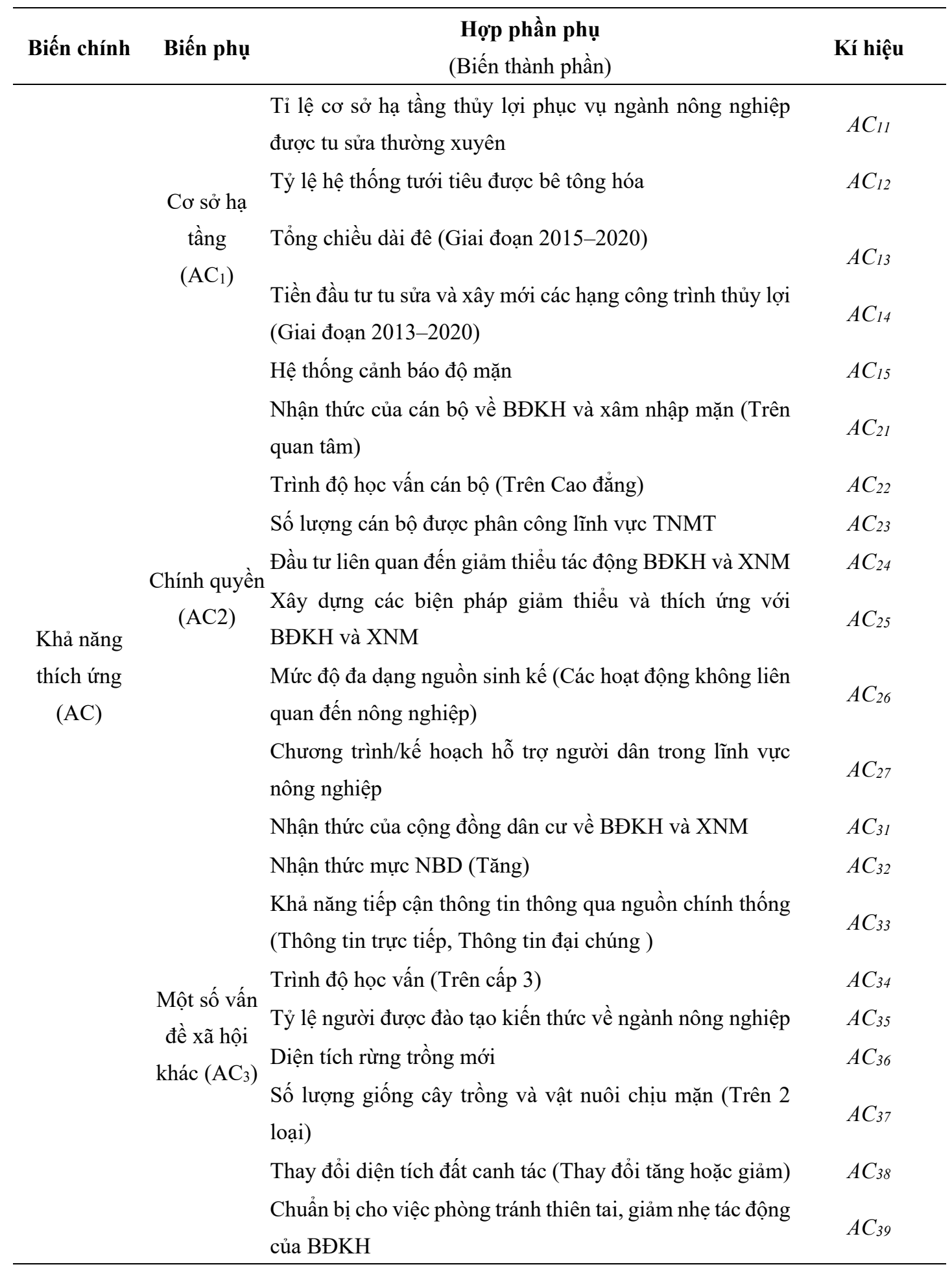


Từ các số liệu thu thập và kết quả phân tích, có thể thấy được khả năng thích ứng của chính quyền và người dân rất được chú ý và quan tâm. Đặc biệt huyện Nghĩa Hưng tuy là huyện chịu ảnh hưởng của XNM lớn nhưng lại có khả năng thích ứng tưng đối tốt so với 2 huyện còn lại (Bảng 11).

Bảng 9. Kết quả tính toán chỉ số khả năng thích ứng AC.

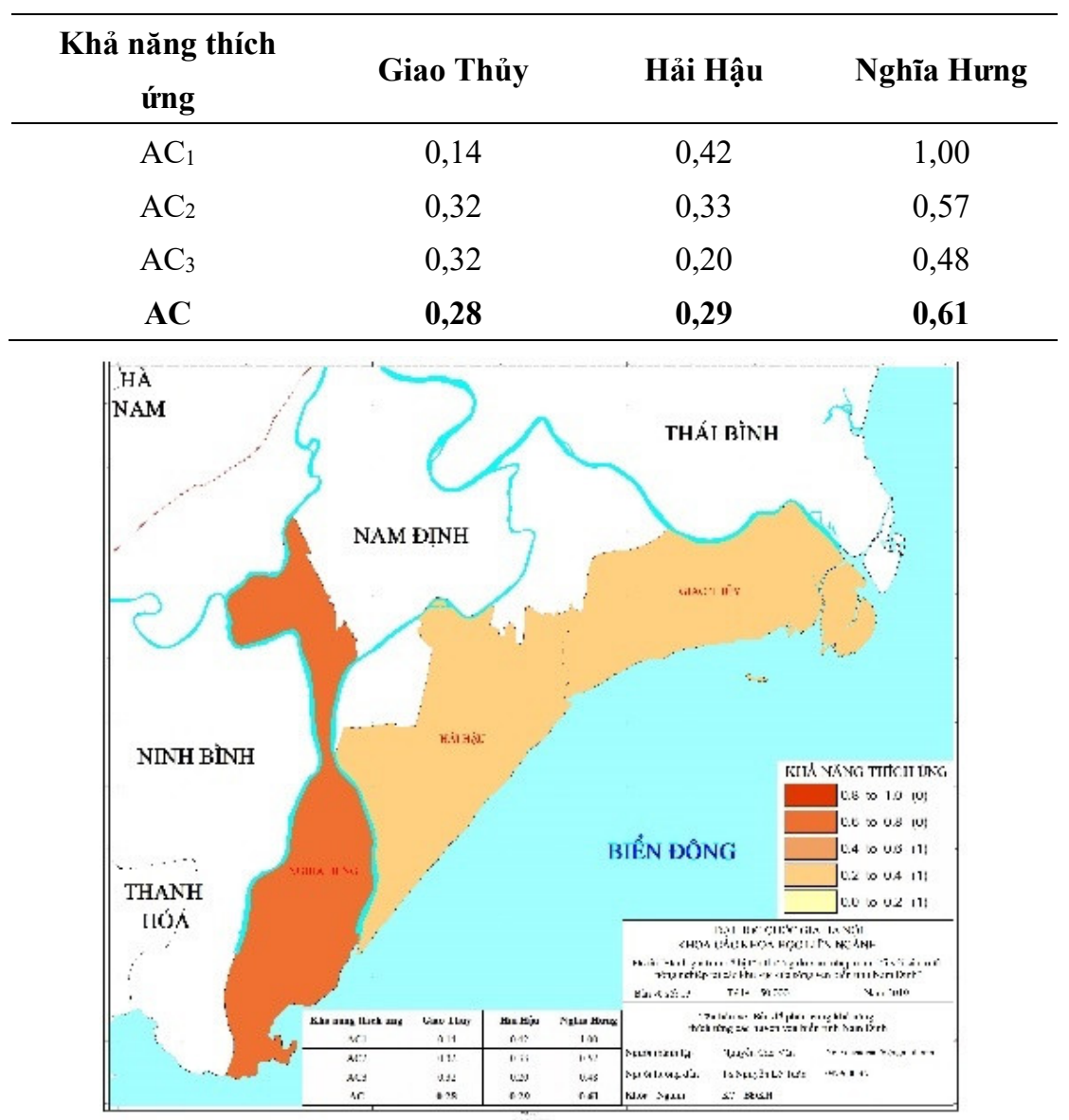

Hình 8. Bản đồ phân vùng khả năng thích ứng $\mathrm{AC}$.

\subsection{4. Đánh giá tính dễ bị tổn thương}

Kết quả của chỉ số dễ bị tổn thương là tập hợp kết quả của ba chỉ số mức độ khắc nghiệt (E), độ nhạy cảm $(\mathrm{S})$ và khả năng thích ứng $(\mathrm{AC})$ (Bảng 12).

Bảng 10. Kết quả tính toán chỉ số tổn thương $\mathrm{V}$.

\begin{tabular}{cccc}
\hline Biến & Giao Thủy & Hải Hậu & Nghĩa Hưng \\
\hline $\mathrm{E}$ & 0,35 & 0,47 & 0,57 \\
$\mathrm{~S}$ & 0,39 & 0,64 & 0,46 \\
$\mathrm{AC}$ & 0,28 & 0,29 & 0,61 \\
$\mathrm{~V}=\frac{E+S+(1-A C)}{3}$ & $\mathbf{0 , 4 9}$ & $\mathbf{0 , 6 1}$ & $\mathbf{0 , 4 7}$
\end{tabular}

Từ kết quả tổng hợp, nghiên cứu đưa ra một số nhận xét như sau: 
- Đối với huyện Nghĩa Hưng tuy mức độ phơi nhiễm cao nhất trong 3 huyện, độ nhạy cảm ở mức trung bình, nhưng khả năng thích ứng đạt $0,61 / 1$. Do vậy, khi tính toán TDBTT thì huyện Nghĩa Hưng có TDBTT thấp nhất là $0,47 / 1$. Từ kết quả, có thể thấy được sự quan trọng của chỉ số khả năng thích ứng. Việc thích ứng tốt với XNM sẽ giảm thiếu đáng kể mực tổn thương do vấn đề đó.

- Ngược lại với huyện Nghĩa Hưng là huyện Hải Hậu, tuy chỉ số độ phơi nhiễm mức trung bình nhưng khả năng thích ứng của huyện lại rất kém dưới $0,3 / 1$. Nên đã khiến huyện có chỉ số TDBTT thuộc dạng nặng nhất là $0,61 / 1$. Điều này xảy ra do huyện là nơi sản suất nông nghiệp lớn nhất trong 3 huyện. Nhưng để thích ứng với XNM thì 2 chỉ số về rừng trồng mới và loại cây trồng, vật nuôi chịu mặn lại rất thấp. Trong khi đó, RNM hay rừng phòng hộ lại là tấm lá chắn cho huyện, cũng là nguồn sinh kế thay thế tốt. Còn thay đổi vật nuôi cây trồng là các thích ứng tốt nhất và nhanh nhất trước các vấn đề XNM. Đó là lý do dẫn tới năng lực thích ứng chỉ có $0,2 / 1$ thấp nhất trong 3 huyện.

- Huyện Giao Thủy tuy có khả năng thích ứng thấp nhất nhưng độ phơi nhiễm thấp và độ nhạy cảm cũng thấp so với 2 huyện còn lại nên chỉ số tổn thương thấp hơn bằng 0,49/1.

Như vậy, từ các thành phần của chỉ số TDBTT được xác định từ công thức (1), cho thấy, mức độ nghịch biến giữa khả năng thích ứng và tính dễ bị tổn thương được thể hiện rất rõ ràng, với khả năng thích yếu kém, cộng thêm độ nhạy cao cảm huyện Hải Hậu dẫn đến TDBTT cao hơn so với 2 huyện còn lại.

\section{Kết luận}

Trong các nghiên cứu liên quan đến XNM, vấn đề đánh giá TDBTT được xem là một vấn đề khó trong nghiên cứu cơ sở lý luận và áp dụng tính toán với thực tế. Điều này không chỉ đối với Việt Nam mà đối với các quốc gia khác trên thế giới. Trong nghiên cứu này, dựa trên phương pháp đánh giá của IPCC, đã tính toán cho 3 huyện có sinh kế của người dân dựa chủ yếu bằng nông nghiệp, gồm: Giao Thủy, Hải Hậu và Nghĩa Hưng. Kết quả nghiên cứu được đánh giá như sau:

1. Từ số liệu về thu thập về thủy văn và thông qua quá trình điều tra khảo sát thực tế, nghiên cứu này đã xây dựng được mô hình tính toán độ mặn cho khu vực nghiên cứu. Kết quả cho thấy ảnh hưởng của XNM đến các huyện ven biển tỉnh Nam Định theo kịch bản RCP 4.5 là khá sâu sắc. Đặc biệt là huyện Nghĩa Hưng do tiếp giáp trực tiếp với 2 con sông và huyện Giao Thủy do diện tích đất ngập nước khá lớn, nền địa hình 2 huyện lại tương đối thấp.

2. Nghiên cứu đã tổng hợp được những thiệt hại do tác động của $X N M$ và khả năng ứng phó của người dân và các sở, ban, ngành có liên quan trong những năm gần đây. Từ đó đánh giá tổng quan được tác động của XNM đến ngành nông nghiệp tại khu vực ven biển tỉnh Nam Định.

3. Nghiên cứu đã tổng hợp và xây dựng được bộ chỉ số với 3 biến chính, 10 biến phụ và 58 hợp phần phụ để đánh giá XNM. Bộ chỉ số này không chỉ áp dụng cho vùng cửa sông ven biển tỉnh Nam Định nói riêng mà có thể áp dụng cho các vùng cửa sông ven biển khác tại Việt Nam. Trên cơ sở đó, đã xác định được TDBTT của ngành nông nghiệp thuộc 3 huyện Giao Thủy, Hải Hậu và Nghĩa Hưng trước bối cảnh XNM đang ngày càng gia tăng và Hải Hậu là huyện có chỉ số tổn thương cao nhất. 


\section{Khuyến nghị}

Trên cơ sở nghiên cứu tại các huyện ven biển tỉnh Nam Định, nghiên cứu đưa ra một số khuyến nghị sau:

- Cần mở rộng nghiên cứu về xâm nhập mặn tới nông nghiệp tại các khu vực, địa phương khác để có cái nhìn toàn diện hơn về tác động của xâm nhập mặn đến các hoạt động nông nghiệp;

- Cần phát triển, khuyến nghị nhân rộng các hoạt động thích ứng hiệu quả tại tỉnh áp dụng cho các địa phương cũng bị ảnh hưởng của xâm nhập mặn khác.

Đóng góp của tác giả: Xây dựng ý tưởng nghiên cứu: N.C.V., N.L.T., P.V.H.; Lựa chọn phương pháp nghiên cứu: N.C.V., N.L.T., P.V.H.; Xử lý số liệu: N.C.V., P.V.H.; Viết bản thảo bài báo: N.C.V., N.L.T., N.T.A., P.V.H.; Chỉnh sửa bài báo: N.C.V., N.T.A., P.V.H.

Lời cảm ơn: Nhóm nghiên cứu xin chân thành cảm ơn sự hỗ trợ của đề tài khoa học "Đánh giá tác động của biến đổi khí hậu đến điều kiện tự nhiên, tài nguyên thiên nhiên và môi trường khu vực cửa sông ven biển vùng đồng bằng sông Hồng và đề xuất giải pháp khai thác sử dụng hợp lý", mã số: BĐKH.33/16-20 trong việc thực hiện và công bố nghiên cứu này.

Lời cam đoan: Tập thể tác giả cam đoan bài báo này là công trình nghiên cứu của tập thể tác giả, chưa được công bố ở đâu, không được sao chép từ những nghiên cứu trước đây; không có sự tranh chấp lợi ích trong nhóm tác giả.

\section{Tài liệu tham khảo}

1. IPCC. Climate change 2007: Impact, Adaptation and Vulnerability, 2007.

2. IPCC. Forth Assessment Report, 2007.

3. Bộ Tài nguyên và Môi trường. Kịch bản biến đổi khí hậu và nước biển dâng cho Việt Nam, 2016.

4. Sở Nông nghiệp và phát triển nông thôn tỉnh Nam Định. Quy hoạch phát triển kinh tế thủy sản và bảo vệ nguồn lợi thủy sản tỉnh Nam Định đến năm 2025, định hướng đến năm 2030, 2018.

5. Bộ Tài nguyên và Môi trường. Ban hành và công bố danh mục các điểm có giá trị đặc trưng mực nước triều vùng ven biển và 10 đảo, cụm đảo lớn của Việt Nam; Bản đồ đường mép nước biển thấp nhất trung bình trong nhiều năm và đường ranh giới ngoài cách đường mép nước biển thấp nhất trung bình trong nhiều năm một khoảng cách 03 hải lý vùng ven biển Việt Nam, 2018.

6. Đức, V.V. Nghiên cứu diễn biến xâm nhập mặn phía Nam Đồng bằng sông Hồng liên quan đến biến đổi khí hậu phục vụ phát triển nông nghiệp, 2017.

7. Allison, E.H. Climate change and fisheries: a comparative analysis of the relative vulnerability of 132 countries Fisheries, 2009.

8. Sở Nông nghiệp và phát triển nông thôn tỉnh Nam Định. Quy hoạch thủy lợi Nam Định, 2012. 


\title{
Assessing the vulnerability and adaptability of saline intrusion to agricultural production in coastal estuaries of Nam Dinh province in the context of climate change
}

\author{
Nguyen Cao Van', Nguyen Le Tuan', Nguyen Thuc Anh'1, Pham Van Hieu' \\ ${ }^{1}$ VietNam Institute of Seas an Island, Vietnam Administrator of Seas and Islands; \\ nguyencaovan.k56@gmail.com; ngletuan1618@gmail.com; thucnguyen.dav@gmail.com; \\ hieupv.env@gmail.com
}

\begin{abstract}
This research presents the results of the analysis and assessment of vulnerability and adaptability with saline intrusion to the agricultural sector in Nam Dinh province in the context of climate change. The applied methodologies based on survey data and hydrological model for calculating salinity index in periods according to the climate change scenarios 2016 of the Ministry of Natural Resources and Environment and the climate change assessment methods suggested in 2007 by IPCC. From this, we assessed the adaptability of the agricultural sector, saline intrusion in 3 main estuaries including Ba Lat, Ninh Co, and Day estuaries (Nam Dinh province); propose vulnerability assessment of each coastal district. Although all aspects have not been considered, the research results have contributed to providing information to Nam Dinh province, giving an overview to serve agricultural planning in the context of climate change.
\end{abstract}

Keywords: Vulnerability; Saline intrusion; Agriculture; Estuaries. 